\title{
The diet of bats from Southeastern Brazil: the relation to echolocation and foraging behaviour
}

\author{
M. Brock Fenton 1 \\ John O. Whitaker Jr. ${ }^{2}$ \\ Maarten J. Vonhof ${ }^{1}$ \\ Jane M. Waterman ${ }^{1}$ \\ Wagner A. Pedro ${ }^{3}$ \\ Ludmilla M.S. Aguiar ${ }^{4}$ \\ Júlio E. Baumgarten ${ }^{5}$ \\ Sylvie Bouchard ${ }^{1}$ \\ Deborah M. Faria ${ }^{5}$ \\ Christine V. Portfors ${ }^{6}$ \\ Naas I.L. Rautenbach ${ }^{7}$ \\ William Scully ${ }_{8}^{1}$ \\ Marlon Zortea ${ }^{8}$
}

\begin{abstract}
In this study the incidence of moths and beetles was examined from feces samples of bats that use different foraging behaviors. Twenty sites around the Fazenda Intervales, a Field Research Station located in São Paulo State, in southeastern Brazil were sampled. Feces were collected from bats caught in mist nets, Tuttle Traps or hand nets and, in one case, from beneath a roost. Feces samples were taken from six species of bats: Micronycteris megalotis (Gray, 1842), Mimon bennettii (Gray, 1838), Furipterus horrens (F. Cuvier, 1828), Myotis riparius Handley, 1960, Myotis ruber (E. Geoffroy, 1806) and Histiotus velatus (I. Geoffroy, 1824). To record and describe the frequencies dominating bat echolocation calls, an Anabat II bat detector coupled with an Anabat ZCA interfaces and DOS laptop computers were used. The data show that Furipterus horrens feeds extensively on moths, as predicted from the features of its echolocation calls. Gleaning bats, whose echolocation calls are much less conspicuous to moths take a wide range of insect (and other) prey.

KEY WORDS. Chiroptera, diet, echolocation, foraging behaviour, southeastern Brazil
\end{abstract}

1) Department of Biology, York University. North York, Ontario, M3J 1P3, Canada.

Corresponding author: M. Brock Fenton. E-mail: bfenton@circus.yorku.ca

2) Department of Life Sciences, Indiana State University. Terre Haute, Indiana 47809, USA.

3) Departamento de Apoio, Producão e Saúde Animal, Universidade Estadual Paulista. Caixa Postal 341, 16050-680 Araçatuba, São Paulo, Brasil.

4) Departamento de Ecologia, Universidade de Brasília. Campus Asa Norte, 70919-970 Brasília, Distrito Federal. Brazil.

5) Departamento de Zoologia, Universidade de Campinas. Caixa Postal 6109, 13083-970 Campinas, São Paulo, Brazil.

6) Department of Neurobiology, Northeastern Ohio Universities College of Medicine. 4209 State Route 44, Post Office Box 95, Rootstown, Ohio 44272-0095, USA.

7) Transvaal Museum. Post Office Box 413, Pretoria, South Africa.

8) Museu de Biologia Professor Mello Leitao. 29650-000 Santa Teresa, Espírito Santo, Brazil. 
The interactions between echolocating bats and insects with bat-detecting ears is a particularly enlightening example of the impact that perceptual abilities can have on predator-prey interactions. FULLARD (1987) and RYDELL et al. (1995) described how the frequencies dominating the echolocation calls of bats directly influenced the conspicuousness of these calls to moths. Differences in the conspicuousness of bats' echolocation calls to moths reflects the fact that moth ears are most sensitive to sounds between 20 and $60 \mathrm{kHz}$ (FULLARD 1987; RYDELL et al. 1995). Three categories of bats use echolocation calls that are relatively inaudible to moths or other insects with bat-detecting ears. First are aerial-feeding bats, those that hunt mainly flying insects, and use echolocation calls dominated by frequencies $<20 \mathrm{kHz}$ and which often feed heavily on moths - e.g. Tadarida teniotis (Rafinesque, 1814) RYDELL \& ARLETTAZ (1994); Euderma maculatum (J.A. Allen, 1891) FULLARD \& DAWSON (1997); Otomops martiensseni (Matschie, 1897) RYDELL \& YALDEN (1997). Second are aerial-feeding bats whose calls are dominated by frequencies $>60 \mathrm{kHz}-$ e.g. many rhinolophids and hipposiderids (JONES 1992). Third are gleaning bats whose echolocation calls are relatively inaudible to moths, species that tend to use low intensity echolocation calls (FAURE et al. 1990); for these species, the role of echolocation in their hunting behaviour remains unclear (FENTON et al. 1995).

The purpose of this study was to examine the incidence of moths and beetles in the feces of a sample of bats that use different foraging behaviour. The aerial feeders used echolocation calls dominated by different frequencies $(<20 \mathrm{kHz} ; 20-60$ $\mathrm{kHz} ;>60 \mathrm{kHz}$ ). It was predicted that aerial feeding bats whose echolocation calls are $<20 \mathrm{kHz}$ and $>60 \mathrm{kHz}$ should feed more on moths than species broadcasting between 20 and $60 \mathrm{kHz}$. Gleaners may show a more variable pattern in the incidence of moths in their diets as reflected in other studies, for example of Antrozous pallidus (Le Conte, 1856) (BELL 1982).

Sampling was made over six species of bats: Micronycteris megalotis (Alonso-Mejía \& Medellin 1991) and Mimon bennettii (PEdro et al. 1994; ORTEGA \& ARITA 1997) are gleaners, and some observations suggest that Furipterus horrens is an aerial feeder (UIEDA et al. 1980), but this species has not been studied in detail. Both Myotis riparius and Myotis ruber also appear to be aerial feeders (unpublished observations) as does Histiotus velatus (W.A. Pedro unpublished observations).

\section{MATERIAL AND METHODS}

Between 4 and 14 January 1997, twenty sites around the Fazenda Intervales, a Field Research Station located in São Paulo State, in southeastern Brazil (24'16'S; $48^{\circ} 24^{\prime} \mathrm{W}$ ) were sampled. In this area, the vegetation is Atlantic forest (pluvial or rain forest). The Fazenda Intervales station is located in an area of karst where limestone caves provide an abundance of roosts for bats. There is no distinct dry season in the area, although precipitation is lower between May and September than at other times of the year (TRAJANO 1996). The annual rainfall ranges between 1000 and $2000 \mathrm{~mm}$ and the mean annual temperature is about $20^{\circ} \mathrm{C}$. 
To describe the frequencies dominating the echolocation calls of bats, an Anabat II bat detector, coupled with an Anabat ZCA interface and DOS laptop computers were used. This system provides no information about the harmonics in the echolocation calls, but indicates the frequencies dominating the calls and the durations of the calls. Echolocation calls of known individuals were recorded from bats flying in the field (light-tagged HovorKA et al. 1996) or in the on site laboratory.

Feces were collected from bats caught in mist nets, Tuttle Traps (TUTTLE 1974) or hand nets and, in one case, from beneath a roost. Feces were examined and analyzed by volume as described by WHITAKER (1988).

\section{RESULTS}

The bats here sampled used a range of frequencies in their echolocation calls (Tab. I). While the Myotis species and Histiotus velatus used high intensity echolocation calls (detectable by the Anabat detector at distances of $\geq 10 \mathrm{~m}$ from the bat), the two gleaners (Micronycteris megalotis and Mimon bennettii) produced echolocation calls of much lower intensity (detectable by the Anabat detector at $<2 \mathrm{~m}$ from the bat). The echolocation calls of Furipterus horrens (Tab. I) were detectable at $\leq 1 \mathrm{~m}$ from the bat by the Anabat detector, probably reflecting their very short durations and the high frequencies in the calls.

Table I. The echolocation calls and foraging behaviour of the bats.

\begin{tabular}{lccccc}
\hline \multirow{2}{*}{ Species } & \multicolumn{3}{c}{ Echolacation calls } & Foraging mode & $\begin{array}{c}\text { Prediction: moths } \\
\text { will dominate diet }\end{array}$ \\
\cline { 2 - 4 } & Highest kHz & Lowest kHz & Duration in ms & & \\
\hline Furipterus horrens & 150 & 120 & $<1$ & unknow & yes \\
Micronycteris megalotis & 94 & 59 & $1-2$ & gleaner & no \\
Mimon bennettii & 180 & 35 & 1 & gleaner & no \\
Myotis sp. cf riparius & 58 & 50 & $4-5$ & aerial & no \\
Myotis sp. cf ruber & 65 & 58 & 5 & aerial & no \\
Histiotus velatus & 25 & 15 & $5-8$ & aerial & yes \\
\hline
\end{tabular}

The data on foraging behaviour (aerial versus gleaner) and frequencies dominating the echolocation calls lead us to predict that two of the aerial-feeders should prey more often on moths than the other aerial feeders (Tab. I). A total of 137 fecal pellets from the 6 species of bats shown in table II were collected and analyzed.

$\mathrm{A} \mathrm{c}^{2}$ test for heterogeneity or independence reveals that Lepidoptera are significantly more often dominant ( $>50 \%$ of the volume of insects encountered) in the feces of Furipterus and Histiotus $\left(\mathrm{c}^{2}=83.87 ; \mathrm{df}=3\right.$; $\left.\mathrm{P}<0.0001\right)$ than in the feces of the Myotis species or those of the gleaners. There were similar significant differences in the opposite direction for Coleoptera in the feces of Myotis and the gleaners versus Furipterus and Histiotus $\left(\mathrm{c}^{2}=56.67 ; \mathrm{df}=3 ; \mathrm{P}<0.0001\right)$. The same pattern of significant differences of Coleoptera and Lepidoptera also prevails when the $c^{2}$ test for heterogeneity or independence is performed on a species by species basis $\left(\mathrm{c}^{2}=155.71, \mathrm{df}=10, \mathrm{P}<0.0001\right)$. In all comparisons the differences are significant. 
Table II. The incidence of moths in the feces of bats sampled.

\begin{tabular}{lcccr}
\hline & \multicolumn{3}{c}{ Bats hunting airbone tergets } & Gleaners \\
\cline { 2 - 4 } & $<20 \mathrm{kHz}$ & $20-100 \mathrm{kHz}$ & $>100 \mathrm{kHz}$ & \\
\hline Number of species & 1 & 2 & 1 & 2 \\
Number of bats/ Number of pellets & $? / 41$ & $7 / 50$ & $2 / 20$ & $3 / 26$ \\
Number of insect orders & 4 & 6 & 20 & 3 \\
Number of Pellets 100\% Lepidoptera & 33 & 6 & 20 & 0 \\
Number of Pellets with any Lepidoptera & 39 & 29 & 0 & 15 \\
Number of Pellets 100\% Coleoptera & 0 & 13 & 26 \\
Number of Pellets with any Coleoptera & 4 & 24 & & 26 \\
\hline
\end{tabular}

\section{DISCUSSION}

The data of this study support earlier predictions about the vulnerability of moths to hunting bats based on the features of bats' echolocation calls and their foraging behaviour (FULLARD 1987; RYDELl et al. 1995). However, like other analyses, the methodology here used does not resolve two important questions about bats' diets, namely the nature of the moths eaten by bats and the description of their diets. Are the moths eaten by bats species with functional bat-detecting ears or those that are deaf or lacking ears? Earless and deaf moths show different patterns of flight (some deaf moths are flightless) behaviour that could influence their exposure to aerial-feeding bats (MORRILL \& FULLARD 1992). The prevalence of Coleoptera in the feces of some species of bats also could complicate generalizations about the vulnerability of beetles to aerial-feeding bats, because some species have bat-detecting ears (YAGER \& SPANGLER 1997).

The data indicate that Furipterus horrens feeds extensively on moths as predicted from the features of its echolocation calls which would be virtually inaudible to moths with hearing-based defenses. The same degree of specialization does not extend to Histiotus velatus whose calls are probably more conspicuous to moths than those of Furipterus, but less so than those of the aerial-feeding Myotis that were studied. Gleaning bats, whose echolocation calls are much less conspicuous to moths (e.g. FAURE et al. 1990) also take a wide range of insect (and other) prey.

ACKNOWLEDGEMENTS. We thank E. Trajano for making the arrangements for working at Fazenda Intervales. We are grateful to D.S. Johnston for reading an earlier version of the manuscript and providing us with comments and to M.K. Obrist for sharing with us his unpublished data about the echolocation calls of Mimon bennettii. This study was supported by a Natural Sciences and Engineering Research Council (Canada) research grant to MBF and by a grant from a Foundation for Research Development (South Africa) grant allocated from the

"Inland Resources Programme" to ILR.

\section{REFERENCES}

Alonso-Mejía \& R.A. MedelLin. 1991. Micronycteris megalotis. Mammalian Species 376: 1-6.

BELL, G.P. 1982. Behavioral and ecological aspects of gleaning by desert insectivorous bat, Antrozous pallidus (Chiroptera: Vespertilionidae). Behav. Ecol. Sociobiol. 10: 217-223. 
FAURE, P.A.; J.H. FULLARD \& R.M.R. BARCLAY. 1990. The response of tympanate moths to the echolocation calls of a substrate gleaning bat, Myotis evotis. Jour. Comp. Physiol. A 166: 843-849.

FEnTon, M.B.; D. AUdET; M.K. OBRIST \& J. RYdELL. 1995. Signal strength, timing and self-deafening: the evolution of echolocation in bats. Paleobiology 21: 229-242.

FULLARD, J.H. 1987. Sensory ecology and neuroethology of moths and bats: interactions in a global perspective, p.244-272. In: M.B. FENTON; P.A. RACEY \& J.M.V. RAYNER (Eds). Recent advances in the study of bats. Cambridge, Cambridge University Press, 350p.

FULLARD, J.H. \& J.W. DAWSON. 1997. The echolocation calls of the spotted bat, Euderma maculatum are relatively inaudible to moths. Jour. Exp. Biol. 200: 129-137.

HOVORKA, M.D.; C.S. MARKS \& E. MULLER. 1996. An improved chemiluminescent tag for bats. Wildl. Soc. Bull. 24: 709-712.

JONES, G. 1992. Bats vs. moths: studies on the diets of rhinolophid and hipposiderid bats support the allotonic frequency hypothesis, p.87-92. In: I. HORÁCEK \& V. VOHRALIK (Eds). Prague studies in mammalogy. Prague, Charles University Press, 380p.

MORRILL, S.B. \& J.H. FuLLARD. 1992. Auditory influences on the flight behaviour of moths in a Nearctic site. I. Flight tendency. Can. Jour. Zool. 70: 1097-1101. OrtegA, J., H.T. ARITA. 1997. Mimon bennettii. Mammalian Species 549: 1-4.

PEDRO, W.A.; C.A.K. Komeno \& V.A. TADDEI. 1994. Morphometrics and biological notes on Mimon crenulatum (Chiroptera: Phyllostomidae). Bol. Mus. Paraens. Emilio Goeldi, sér. Zool., 10: 107-112.

RYDELL, J. \& A. ARLETTAZ. 1994. Low-frequency echolocation enables the bat Tadarida teniotis to feed on tympanate insects. Proc. Roy. Soc. London B. 257: 175-178.

RYDELL, J.; G. JONES \& D. WATERS. 1995. Echolocating bats and hearing moths: who are the winners? Oikos 73: 419-424.

RYDELL, J. \& D.W. YALDEN. 1997. The diets of two high-flying bats from Africa. Jour. Zool., London, 242: 69-76.

TrajANO, E. 1996. Movements of cave bats in southeastern Brazil, with emphasis on the population ecology of the common vampire bat, Desmodus rotundus (Chiroptera). Biotropica 28: 121-129.

TUTTLE, M.D. 1974. An improved trap for bats. Jour. Mammal. 55: 475-477.

UiedA, W.; I. SAZIMA \& A. STORTI-FILHO. 1980. Aspectos da biologia do morcego Furipterus horrens (Mammalia, Chiroptera, Furipteridae). Rev. Brasil. Biol. 42: 505-513.

WHITAKER JR., J.O.. 1988. Food habiats analysis of insectivorous bats, p.171-189. In: T.H. KUNZ (Ed.). Ecological and behavioral methods for the study of bats. Washington, D.C., Smithsonian Institution Press, 544p.

YAGER, D.D. \& H.G. SPANGLER. 1997. Behavioral response to ultrasound by the tiger beetle Cicindela marutha Dow combines aerodynamic changes and sound production. Jour. Exp. Biol. 200: 649-659.

Recebido em 16.VI.1998; aceito em 29.IX.1999. 